\title{
Knowledge, Attitude and Practice of Mothers of Children Below Five Years Regarding Diarrhoea
}

\author{
Dipak Kumar Gupta ${ }^{1}$, Poonam Kumari Sah ${ }^{2}$ \\ ${ }^{1}$ Department of Paediatrics, Janaki Medical College, Janakpur; \\ ${ }^{2}$ Department of Community Medicine, Janaki Medical College, Janakpur. \\ Correspondence: \\ Dr. Dipak Kumar Gupta, Email: drdipakkumargupta@gmail.com
}

Background: The public health problem of diarrhoeal diseases is widespread. In order to reduce related mortality and morbidity, caretakers must play an active role and need to determine to what extent they are empowered.

Method: A cross sectional descriptive study was conducted from March 7- April 6, 2021 among 113 mothers of children below five years who visited hospital-seeking treatment for diarrhoeal diseases of their children. A self-structured questionnaire regarding knowledge, attitude and practice regarding was used to generate data on interview basis.

Results: Knowledge regarding the diarrhoeal disease was found to be of good level (88.4\% correctly defining diarrhoea). Majority of mothers has good attitude towards diarrhoea. However, far few mothers correctly recognised signs of dehydration, 23 recognizing dry mucosa and 44 recognizing sunken eyes. Out of total, $81 \%$ participants knew about oral rehydrate solutions.

Conclusion: Despite good knowledge and attitudes towards diarrhoea among mothers with children under five years of age, the standard of home-based management was found to be unsatisfactory based on the results of the study.

Keywords: Attitude; diarrhoea; knowledge; practice.

\section{INTRODUCTION}

In children of age group from one months to five years, diarrhoea is still the second leading cause of death globally. ${ }^{1}$ In the world, 525,000 children die each year from diarrhoea, about 2195 each day, accounting for $8 \%$ of all under-5-year-mortality. The number of diarrhoea episodes among children younger than 5 years old has exceeded 1.7 billion annually. ${ }^{2}$ Nepal had 1193 diarrhoea-related deaths under five in 2017, according to the WHO. Not only do children die, but they suffer stunting and malnutrition as well. ${ }^{3}$ The Rotavirus is one of the most prevalent diarrhoeal pathogens, which can result in fluid, electrolyte, and nutritional deficiency in the intestinal tract, which can potentially lead to dehydration and even death. Under five-diarrhoea disease is aggravated by contaminated weaning food, poor feeding practices, limited sanitary disposal of waste, poor living conditions, and inadequate and expensive health care. Diarrhoea is not fatal in and of itself; the lack of knowledge, poor practices, and wrong attitude of mothers towards its management and prevention contribute to a severe dehydration and ultimately death. ${ }^{2}$ The aim of this study was to investigate mothers' knowledge, attitude, and practice regarding diarrhoea in children under Citation: Gupta DK, Sah PK. Knowledge, attitude and practice of mothers of children below five years regarding diarrhoea. Nepal J Health Sci. 2021 Jan-Jun;1(1): 16-20 


\section{METHODS}

A descriptive cross-sectional study was conducted at Janaki Medical College from March 7, 2021- April 6, 2021. In the study, 113 caregivers with their children who were brought to hospital for diarrhoea were studied. Participants in this study were selected based on the non-probability purposive sampling technique. Mothers with children having severe diarrhoeal complications, malabsorption syndromes and food allergies were not included in the study. In addition, mothers with a physical impairment (unable to hear or speak) and those with mental illness were also not included. Before the collection of data, detailed explanations about the study to all the subjects were provided and obtained their informed consent voluntarily. Data collected by using a face-to-face interview, which included a structured questionnaire containing questions about sociodemographic, knowledge, attitude and practice of the mothers regarding diarrhoeal diseases of under-5-year-olds. For data quality control, the investigator conducted the interview with the participants and filled the data in the proforma prepared. All the data collected were entered in Microsoft Excel 2016 and IBM-SPSS 23.0 was used for statistical analysis. The categorical data were expressed in proportion and percentage. The continuous data was presented in mean and standard deviation. Ethical approval was obtained from Janaki Medical College -Institutional Review Committee.

\section{RESUltS}

The mean age of study participants was $23 \pm 6.3$ years, with more than half of mothers (52\%) in age group 21-25 years. Out of all study participants, $86 \%$ of mothers belonged to joint family with average family member's size of nine.

Table 1: Socio- Demographics study of participants $(n=113)$

\begin{tabular}{|c|c|c|c|}
\hline \multicolumn{2}{|c|}{ Variable } & Number & Percentage \\
\hline \multirow{3}{*}{ Education } & Less than X & 49 & 43.4 \\
\cline { 2 - 4 } & High School (XI- XII) & 37 & 32.7 \\
\cline { 2 - 4 } & Undergraduate & 19 & 16.8 \\
\hline \multirow{2}{*}{ Employment } & Graduate & 8 & 7.1 \\
\hline & Household & 75 & 66.4 \\
\hline & Employed & 38 & 33.6 \\
\hline
\end{tabular}

As shown in table 1, most of the mothers included in the study has education below class ten (43.4\%) and only $7.1 \%$ of the mothers has graduate level of education. The majority of the mothers were household (66.4\%) and rest $33.6 \%$ were employed.

Table 2: Knowledge of Mothers of children under five years

\begin{tabular}{|l|c|c|c|}
\hline \multicolumn{2}{|l|}{ Variables } & Number & Percentage \\
\hline \multirow{3}{*}{ What is diarrhoea? } & Loose stool > 3 times/ day & 100 & 88.5 \\
\hline & Loose stool> 2 times/ day & 40 & 35.4 \\
\hline & Normal stool> 3 times/ day & 9 & 0.1 \\
\hline & Eating with dirty hands & 85 & 75.2 \\
\hline & Drinking unclean water & 85 & 75.2 \\
\hline & Eating unhygienic food & 85 & 75.2 \\
\hline \multirow{3}{*}{ Etiologies of diarrhoea } & Evil eye & 30 & 26.5 \\
\hline & Teething & 19 & 16.8 \\
\hline & Unclean fed bottle & 62 & 54.9 \\
\hline & Worm infestation & 71 & 62.8 \\
\hline & Eating mud & 80 & 70.8 \\
\hline
\end{tabular}


From the above table, it shows that the majority of the mothers (88.49\%) defined diarrhoea with loose stool greater than 3 times a day while $35.4 \%$ defined the diarrhoea as loose stool more than 2 times per day. Majority of the respondents believe that eating with dirty hands (75.2\%), drinking unclean water (75.2\%), eating unhygienic food (75.2\%) and eating mud (70.8\%) causes diarrhoea and more than half of the respondents believe that diarrhoea is due to unclean fed bottle (54.9\%) and worm infestation (62.8\%).

Table 1: Socio- Demographics of study participants $(n=113)$

\begin{tabular}{|l|c|c|}
\hline \multicolumn{1}{|c|}{ Variables } & Numbers & Percentage \\
\hline Cease breast feeding & 22 & 19.5 \\
\hline Breastfeeding continued & 54 & 47.8 \\
\hline Do not know & 37 & 32.7 \\
\hline Proper use of toilet & 82 & 72.6 \\
\hline Drinking boiled water & 90 & 79.6 \\
\hline Symptoms & & \\
\hline Dry buccal & 23 & 20.4 \\
\hline Skin turgor & 9 & 8.0 \\
\hline Cold extremities & 28 & 24.8 \\
\hline Sunken eyes & 44 & 38.9 \\
\hline Thirst & 39 & 34.5 \\
\hline Danger sign & & \\
\hline Blood in stool & & 55.8 \\
\hline Vomiting & 63 & 63.7 \\
\hline
\end{tabular}

From table 3, 22 (19.5\%) mothers reported that they cease breastfeeding when a child is sick with diarrhoea, whereas 54 (47.8 \%) mothers strongly believed that breast-feeding continuation is necessary when children have diarrhoea. Rest 37 (32.7\%) responded do not know. The use of a latrine prevents diarrhoea according to 82 mothers and drinking boiled water prevents diarrhoea according to 90 mothers.

When it came to recognizing diarrhoea symptoms, 23 mothers knew that dry buccal mucosa is a sign, nine knew that skin turgor is a sign, 28 knew that cold extremities are a sign, 44 knew that sunken eyes as a sign and 39 knew that marked thirst is a sign. While 63 mothers noted blood in stool as a sign of danger, 72 cited an increase in vomiting as a sign of danger.

Table 4: Practice of mothers under five regarding diarrhoea $(n=113)$

\begin{tabular}{|l|c|c|c|}
\hline \multicolumn{1}{|c|}{ Variables } & Number & Percentage \\
\hline Treatment of diarrhoea possible at & Agree & 27 & 23.9 \\
\hline homes & Disagree & 86 & 76.1 \\
\hline \multirow{2}{*}{ Know about ORS } & Yes & 92 & 81.4 \\
\hline \multirow{2}{*}{ Prepare ORS } & No & 21 & 18.6 \\
\hline \multirow{2}{*}{ Treatment seek at } & Correct & 51 & 45.1 \\
\hline & Incorrect & 62 & 54.9 \\
\hline & Hospital & 96 & 85.0 \\
\hline
\end{tabular}

From table 3, 22 (19.5\%) mothers reported that they cease breastfeeding when a child is sick with diarrhoea, whereas 54 (47.8 \%) mothers strongly believed that breast-feeding continuation is necessary when children 
have diarrhoea. Rest 37 (32.7\%) responded do not know. The use of a latrine prevents diarrhoea according to 82 mothers and drinking boiled water prevents diarrhoea according to 90 mothers.

When it came to recognizing diarrhoea symptoms, 23 mothers knew that dry buccal mucosa is a sign, nine knew that skin turgor is a sign, 28 knew that cold extremities are a sign, 44 knew that sunken eyes as a sign and 39 knew that marked thirst is a sign. While 63 mothers noted blood in stool as a sign of danger, 72 cited an increase in vomiting as a sign of danger.

\section{DisCUSSIONS}

Worldwide, diarrhoea is a problem, and there may be different beliefs and practices among mother about diarrhoea. It is likely that several different factors can influence beliefs and practices, which can differ according to the region, country, ethnicity, culture, and geographic location. In children under the age of five, it is the leading cause of morbidity and mortality. It is crucial to assess the knowledge, attitude, and practice (KAP) of the mothers of under five children regarding diarrhoea and to promote health education for them. The awareness of causes and management at home of childhood diarrhoea is crucial in order to reduce mortality and morbidity related to diarrhoea. ${ }^{4}$

Ours study demonstrated good level of knowledge among mothers of children below five regarding diarrhoea. The finding was better than similar studies conducted in India ${ }^{5}$ and Nigeria ${ }^{6}$. Janakpur is provincial capital of State 2 of Nepal. A major target area of Government of Nepal's mass media efforts was Janakpur, where radio messages were used to raise awareness among Janakpur residents regarding diarrhoea and Oral Rehydration Solution. The knowledge was found to be better than community based study conducted in Dharan, Nepal in from 1997-1998.7

Likewise, few believed evil eye and teething as a cause of diarrhoea in current study. Witchcraft and teething was thought to cause of diarrhoea by some respondent in a qualitative study conducted in Morang, Nepal. ${ }^{8}$
The finding was higher than similar study conducted in Ethiopia. ${ }^{2}$ Socio-cultural differences are likely to explain the discrepancy.

The knowledge among mothers to recognize dehydration signs was low. We, therefore suggest, more mass media intervention to educate mothers regarding recognizing signs of dehydration.

The majority of mothers knew about Oral Rehydrate Solution, even though few believed that diarrhoea could be treated at home. Study in Ethiopia ${ }^{2}$ produced lower results than this study.

However less than half knew procedure to prepare ORS correctly. Because these mothers lack formal education, they might not be familiar with ORS mixing. The outcome of this study was lower than that of the Morang study. ${ }^{8}$

A vast majority of mothers in the study sought medical treatment at hospital for their children during the time of diarrhoeal sickness. Since Janakpur is well connected to the health care system, women have more access to health care services.

\section{CONCLUSIONS}

This study concludes that there is still a lot of gap and room for improvement in the knowledge, attitude and practice of mothers of children under five regarding diarrhoea. It is strongly recommended that effective interventions be made through mass media or education.

\section{REFERENCES}

1. Liu L, Oza S, Hogan D, Chu Y, Perin J, Zhu J, et al. Global, regional, and national causes of under-5 mortality in 2000-15: an updated systematic analysis with implications for the Sustainable Development Goals. The Lancet. 2016 Dec 17;388(10063):3027-35.

2. Shine S, Muhamud S, Adanew S, Demelash A, Abate M. Prevalence and associated factors of diarrhoea among under-five children in Debre Berhan town, Ethiopia 2018: a cross sectional study. BMC Infect 
1. Dis. 2020 Feb 24;20. Available from: https://www.ncbi.nlm.nih.gov/pmc/articles/PMC7041267/

2. Li R, Lai Y, Feng C, Dev R, Wang Y, Hao Y. Diarrhoea in under Five Year-Old Children in Nepal: A Spatiotemporal Analysis Based on Demographic and Health Survey Data. Int J Environ Res Public Health. 2020 Mar 23;17(6).

3. Mathiazhakan U. A Study To Assess The Knowledge, Attitude And Practice Of Caregiver Of Children Admitted With Diarrhoea At Kmch Hospital Coimbatore. Int J Pharm Biol Sci. :7.

4. Prasanna, V., Rani, Leo Sequeira Vaz, Kusneniwar Gn, V. Prasanna, and Rani. Knowledge and Attitude of Mothers about Diarrhoea, ORS and Feeding Practices in Under-Five Children in a Rural Area of Ranga Reddy, Telangana.JMSCR. 2016; 4(10), no. 10: 13201-209.

5. Ogunrinde OG, Raji T, Owolabi OA, Anigo KM. Knowledge, Attitude and Practice of Home Management of Childhood Diarrhoea among Caregivers of Under-5 Children with Diarrhoeal Disease in Northwestern Nigeria. J Trop Pediatr. 2012 Apr 1;58(2):143-6

6. Rehan H, Gautam K, Gurung K. Mothers Needs To Know More Regarding Management Of Childhood Acute Diarrhoea. Indian J Prev Soc Med. 2003;34(1).

7. Ansari M, Ibrahim MIM, Hassali MA, Shankar PR, Koirala A, Thapa NJ. Mothers' beliefs and barriers about childhood diarrhoea and its management in Morang district, Nepal. BMC Res Notes. 2012 Oct 24;5(1):576. 